product was quickly removed to a boat and carefully distilled in an atmosphere of carbon dioxide. Brown vapors were expelled from the boat, which finally contained nothing but white silica. The brown vapors quickly condensed in the colder portion of the tube, and upon analysis gave results varying between those required by the tetrachloride and pentachloride.

The conclusion to be drawn from these experiments then is that notwithstanding the molybdenum atom has already been partially chlorinated, and apparently is in a suitable condition to pass into the hexachloride, it yet does not do so, and we can hence only say that the molybdenum is either not sexivalent towards chlorine, or that at the elevated temperature at which these reactions took place, the hexachloride, if formed, cannot exist, but is dissociated into lower chlorinated derivatives.

On heating pure, finely divided molybdenum, intimately mixed with sugar-carbon, in an atmosphere of chlorine the invariable product was the pentachloricle.

The temperature doubtless exerts a great influence in these reactions.

It has been observed in this laboratory that when metallic molybdenum acts upon an aqueous solution of ferric chloride rapid reduction of the ferric salt ensues with accompanying solution of the molybdenum. From a careful determination of the amount of iron thus reduced, the molybdenum evidently dissolves as a hexad, and it may be that if such solutions were allowed to evaporate slowly in desiccators, the hexachloride or some double salt, formed from it and ferrous chloride, might be found. Search will be made in this direction.

CNiversity of PenNsylvania, June, 1894 .

\title{
THE ACTION OF HYDROCHLORIC ACID GAS UPON SODIUM VANADATE.
}

BY EDGAR F. SMITH AND JOS. G. MIBIS.

Recuived , une 18,1894 .

\footnotetext{
$T \mathrm{HE}$ reaction of Debray' - the volatilization of molybdic acid by means of hydrochloric acid gas, - has suggested a number of experiments which of late have been tried in various 1 Compt. rend., 46, 1098 .
} 
directions in this laboratory. Among others we have exposed sodium pyrovanadate to the influence of the gas at temperatures ranging from the ordinary to about $440^{\circ} \mathrm{C}$, and have found that $\mathrm{j}^{+}$is possible in this manner to eliminate the vanadic acid from its salts.

In several experiments we used a preparation from Merck, marked "sodium vanadate." It was not white in color, but showed here and there spots that were yellow to reddish-brown. Weighed portions of this salt, after complete drying, were exposed in boats, to the action of pure hydrochloric acid gas. As soon as the boats were introduced into the gas the salt, in the cold, acquired a red-brown color. On the application of a gentle heat, vapors of similar color appeared over the boat and condensed in the colder, anterior portion of the combustion tube to a reddish-brown, semi-transparent, oily liquid, which was taken up by water with a brown color. In the boat remained sodium chloride, containing here and there minute black spots. On dissolving the salt, the black insoluble material was carefully examined and proved to be traces of vanadic oxide. They were undoubtedly present in the original salt and were the real cause of the reddish color noted in it. That they were not volatilized may be due possibly to the fact that they had previously undergone strong ignition, and were hence less volatile, although it was observed that by continued heating of the salt, while yet exposed to hydrochloric acid vapor, they gradually grew less in quantity. The results obtained in the four experiments, which follow, while they do not agree with the theoretical requirements yet show that the source of error was constant.

I. 0.0795 gram sodium vanadate gave 0.0546 gram sodium chloride, whereas if the salt analyzed had been pure sodium pyrovanadate it should have given 0.0606 gram sodium chloride.

2. 0.0786 gram sodium vanadate gave $0.0535 \mathrm{gram}$ sodium chloride, instead of 0.0599 gram.

3. 0.1006 gram vanadate gave 0.0683 gram sodium chloride, instead of 0.0767 gram.

4. 0.1322 gram vanadate gave 0.09 I 6 gram sodium chloride, while theory required $0.1007 \mathrm{gram}$.

Taking the purest vanadic acid that we could find, pyrovana- 
date of sodium was prepared and obtained pure after several recrystallizations. The anhydrous material was exposed to hydrochloric acid gas as before with results that indicate a quantitative separation of the acid.

I. 0.1240 gram sodium pyrovanadate heated to $440^{\circ}$ in hydrochloric acid gas gave 0.0935 gram of salt instead of 0.0945 gram.

2. 0.2197 gram sodium pyrovanadate gave 0.1669 gram sodium chloride, while theory requires 0.1672 gram.

The sodium chloride from these last two experiments was perfectly white in color, soluble without residue in water, and on examination showed no evidence of the presence of vanadium. The volatile product had the appearance of the compound $2 \mathrm{VO}_{3} \cdot 3 \mathrm{H}_{2} \mathrm{O} .4 \mathrm{HCl}$ obtained by Berzelius when acting on vanadic acid with concentrated hydrochloric acid. If such be really the case we may suppose that in our reaction changes occurred similar to those indicated in the following equations:

I. $\mathrm{Na}_{4} \mathrm{~V}_{2} \mathrm{O}_{4}+4 \mathrm{HCl}=4 \mathrm{NaCl}+\mathrm{V}_{2} \mathrm{O}_{5} \cdot 2 \mathrm{H}_{2} \mathrm{O}$,

II. $\mathrm{V}_{2} \mathrm{O}_{6} \cdot 2 \mathrm{H}_{2} \mathrm{O}+6 \mathrm{HCl}=2 \mathrm{VO}_{2} \cdot 3 \mathrm{H}_{2} \mathrm{O} .4 \mathrm{HCl}+\mathrm{Cl}_{2}$.

It will, however, be necessary to subject this volatile product to careful analysis before making a positive assertion in regard to its composition.

It is our intention to pursue this study further with the view of ascertaining whether by means of this reaction it will be possible to separate vanadic acid from certain of its associates from which it is now removed with difficulty. From the ease with which the transposition occurs we may hope that the atomic mass of vanadium may be determined after the same fashion as was done in the case of molybdenum.'

UNIVESITY OF PENNSYLVANIA.

June, I894.

\section{ON SOME OF THE ARSENIC TESTS OF THE U. $S$. PHARMACOPOEIA $(1890) .^{2}$}

by Charles O. Curtuan.

Received June 15,1894 .

Note.-In applying Bettendorf's test for arsenic, the Pharmacopoeia directs that to a small quantity of the liquid to be tested, which should contain much hydrochloric acid, or should be a solution of the substance

1 Ztschr.anorg. Chem., 5, 280.

2 Report of the Pharmacopoeial Research Committee B. 